\title{
Construção e avaliação agronômica de genótipos de cornichão com respostas contrastantes à toxidez por alumínio ${ }^{1}$
}

\author{
Armando Martins dos Santos ${ }^{2}$, Miguel Dall'Agnol' ${ }^{2}$, Aline Janke ${ }^{2}$, Carlos Alberto Bissani ${ }^{2}$, \\ Luciana Carvalho dos Santos ${ }^{2}$, Marcos Laux de Leão ${ }^{2}$ \\ 1 Trabalho financiado pelo projeto Lotassa. \\ 2 Faculdade de Agronomia da Universidade Federal do Rio Grande do Sul. Av. Bento Gonçalves, 7712 - Caixa Postal 15100 - 91540-000.
}

RESUMO - Este trabalho foi realizado com o objetivo de selecionar e caracterizar genótipos de Lotus corniculatus com respostas contrastantes à toxidez por alumínio. Quatro cultivares (São Gabriel, San Gabriel, Draco, Estanzuela) e uma população (UFRGS) foram submetidas a duas seleções consecutivas em solos com 30-35\% de saturação por alumínio. As seleções consistiram da separação de $1 \%$ dos indivíduos mais e menos vigorosos para obtenção de genótipos tolerantes e sensíveis, respectivamente. Os indivíduos selecionados foram comparados ao germoplasma de origem por avaliação agronômica. Os genótipos selecionados pela tolerância ao alumínio tóxico foram de modo geral superiores aos germoplasmas originais, enquanto aqueles selecionados pela sensibilidade parecem ter sido selecionados pelo menor vigor, pois foram inferiores ao germoplasma original, mesmo em situações de ausência de alumínio tóxico. Entre os genótipos selecionados, destacou-se o UFRGS selecionado para tolerância, que apresentou elevada produção de matéria seca, sendo superior aos demais genótipos. A realização de testes a campo e a multiplicação de sementes destes genótipos para posterior uso em áreas que apresentem esta limitação é necessária, particularmente para a população de UFRGS selecionada para tolerância ao alumínio.

Palavras-chave: acidez do solo, Lotus corniculatus, melhoramento genético, tolerância ao alumínio

\section{Construction and agronomic evaluation of birdsfoot trefoil genotypes with contrasting responses to aluminum toxicity}

\begin{abstract}
The objective of this study was to select and characterize Lotus corniculatus genotypes with contrasting responses to toxicity by aluminum. Four cultivars (São Gabriel, San Gabriel, Draco, Estanzuela) and one population (UFRGS) were submitted to two consecutive selections in soils that presented 30-35\% aluminum saturation. Selections consisted of separating $1 \%$ of the most and less vigorous individuals in order to obtain tolerant and sensitive genotypes, respectively. The individuals chosen were compared with the original germplasm by agronomical evaluation. Genotypes selected by tolerance to toxic aluminum were overall superior to the original populations. However, the materials chosen by sensitivity were inferior to the original populations even in situations where toxic aluminum was absent. Among the selected genotypes, the UFRGS selected for tolerance stood out, presenting an elevated dry matter production level - superior to all other genotypes. Field testing and seed multiplication of these genotypes for further use in areas that present this limitation is necessary, especially for the UFRGS population selected for tolerance to aluminum.
\end{abstract}

Key Words: aluminum tolerance, breeding, Lotus corniculatus, soil acidity

\section{Introdução}

Os estresses ambientais estão entre os fatores mais limitantes à produção vegetal na Região do Cone Sul da América do Sul. A acidez do solo destaca-se neste cenário, principalmenteno Brasil, Chile e Uruguai, sendo um importante fator limitante da produtividade das pastagens nesta região (Foy, 1978; Rao et al., 1993; Kochian et al., 2005).

Os solos ácidos constituem aproximadamente $30 \mathrm{a}$ $40 \%$ das terras aráveis em regiões tropicais e temperadas
(Von Uexküll \& Mutert, 1995), sendo a toxidez por alumínio o primeiro fator limitante da produção vegetal nessas situações. Em condições de pH do solo abaixo de 5,5, formas tóxicas de alumínio são solubilizadas no solo, inibindo o crescimento radicular e reduzindo a capacidade de absorção de nutrientes e água (Samac \& Tesfaye, 2003). Além disso, devido ao alto conteúdo de óxidos de ferro e alumínio dos oxissolos, uma grande fração do fosfato é adsorvida, ficando indisponível para as plantas (fosfato insolúvel). 
Das espécies que desempenham importante papel na produtividade de pastagens cultivadas da América do Sul, destacam-se algumas do gênero Lotus (principalmente no Uruguai e Argentina), como L. glaber, L. subbiflorus, L. corniculatus e L. uliginosus (Pavlovkin et al., 2009), que possuem bom valor forrageiro, capacidade de fixar nitrogênio no solo e produções superiores às de outras leguminosas cultivadas em locais com moderada fertilidade do solo (baixos teores de P e K) (Blumenthal \& McGraw, 1999). Entre estas espécies, L. corniculatus é, sem dúvida, a espécie com maior importância agronômica e ampla distribuição de utilização (Díaz et al., 2005). Uma grande variabilidade tem sido observada para diversas características de interesse agronômico e para uso desta espécie em condições adversas (Papadopoulos \& Kelman, 1999). Essa variação fornece aos melhoristas a oportunidade de selecionar genótipos superiores e desenvolver cultivares mais adaptadas a condições adversas, como, por exemplo, para tolerância ao alumínio tóxico.

Por se tratar de uma espécie alógama e tetraploide, o progresso obtido no melhoramento tradicional é mais difícil e demorado (Kirkbride, 1999; Steiner, 1999). Além disso, diversos mecanismos que levam a planta a sobreviver e produzir sob estresses ambientais envolvem características complexas e de difícil avaliação, tornando esta tarefa ainda mais desafiadora. No entanto, resultados positivos têm sido obtidos nesta espécie pelo uso da seleção massal (Papadopoulos \& Kelman, 1999).

Objetivou-se com este trabalho selecionar genótipos de Lotus corniculatus com respostas contrastantes ao alumínio tóxico e realizar a caracterização agronômica dos genótipos selecionados e do germoplasma que lhes deram origem.

\section{Material e Métodos}

Este trabalho foi realizado entre junho de 2006 e janeiro de 2009 em casas-de-vegetação e no Laboratório de Análise Genética, localizados no Departamento de Plantas Forrageiras da Faculdade de Agronomia da Universidade Federal do Rio Grande do Sul (UFRGS).

Em 24 de abril de 2006, foram semeadas 2.000 sementes para cada uma das quatro cultivares (São Gabriel, San Gabriel, Draco, La Estanzuela) e para uma população (UFRGS) de L. corniculatus em bandejas com capacidade para $8 \mathrm{~kg}$ de solo com níveis de saturação por alumínio na CTC do solo de $34,4 \%$ e $32,5 \%$. Após um período de 60 dias (24 de junho de 2006), foi realizada a seleção do germoplasma original, baseando-se no vigor e desenvolvimento da parte aérea, impondo pressão de seleção de $1 \%$. Foram selecionadas as 20 melhores e as 20 piores plantas de cada bandeja. As plantas selecionadas foram identificadas como tolerantes e sensíveis (as cinco populações originais geraram 10 populações - cinco denominadas tolerantes e cinco sensíveis). Estas foram transplantadas para vasos com capacidade para $5 \mathrm{~kg}$ de substrato comercial, sendo cultivadas em casa-de-vegetação. Estas casas-de-vegetação foram completamente vedadas com tela antiafídeo e, visando maximizar o florescimento, um sistema de iluminação foi montado utilizando lâmpadas do tipo HQI-TS, na densidade de uma lâmpada para cada $2 \mathrm{~m}^{2}\left(500 \mu \mathrm{mol} \mathrm{m} \mathrm{m}^{-2} \mathrm{~s}^{-1}\right.$ e 16 horas de fotoperíodo). O início do florescimento ocorreu em setembro de 2007.

Os cruzamentos foram realizados de forma manual, retirando-se as alas e a quilha com auxílio de uma pinça. $\mathrm{O}$ pólen foi coletado em uma placa de Petri e um pincel de cerdas bem macias foi utilizado para a realização da polinização dos estigmas expostos.

Os legumes produzidos foram colhidos e levados à estufa de ventilação forçada, com temperatura entre 28 e $30^{\circ} \mathrm{C}$, por um período de 96 horas. Após a secagem, os legumes foram trilhados e as sementes submetidas a um processo de limpeza em peneiras manuais e passadas por soprador visando à eliminação de sementes chochas. As sementes foram então mantidas em refrigerador $\left(4^{\circ} \mathrm{C}\right)$ até sua utilização. Após coleta, processamento e obtenção de $3 \mathrm{~g}$ de sementes de cada um dos 10 genótipos (genótipos tolerantes e sensíveis), em janeiro de 2008, suspenderam-se os cruzamentos do primeiro ciclo de seleção.

As sementes obtidas por cruzamentos realizados nos genótipos originais constituíram os genótipos Draco $\mathrm{F}_{1}$ (DR-T $\mathrm{D}_{1}$ e DR- $\mathrm{S}_{1}$, genótipo tolerante e sensível, respectivamente), Estanzuela $\mathrm{F}_{1}\left(\mathrm{ES}-\mathrm{T}_{1}\right.$ e ES- $\left.\mathrm{S}_{1}\right)$, San Gabriel F $_{1}\left(\mathrm{SA}_{1} \mathrm{~T}_{1} \text { e SA-S }\right)_{1}$, São Gabriel F ${ }_{1}\left(\mathrm{SG}-\mathrm{T}_{1}\right.$ e SG-S $\left.{ }_{1}\right)$ e UFRGS $\mathrm{F}_{1}\left(\mathrm{UF}-\mathrm{T}_{1}\right.$ e UF-S $\mathrm{S}_{1}$ ), os quais passaram pelo segundo ciclo de seleção entre setembro de 2008 e janeiro de 2009, pela mesma metodologia utilizada anteriormente, visando aumentar a tolerância ou sensibilidade ao alumínio.

As sementes obtidas do novo ciclo formaram os genótipos Draco $\mathrm{F}_{2}\left(\mathrm{DR}-\mathrm{T}_{2}\right.$ e DR- $\mathrm{S}_{2}$, genótipo tolerante e sensível, respectivamente), Estanzuela $\mathrm{F}_{2}\left(\mathrm{ES}-\mathrm{T}_{2}\right.$ e ES-S $\mathrm{S}_{2}$, São Gabriel $\mathrm{F}_{2}\left(\mathrm{SG}_{2} \mathrm{~T}_{2} \text { e SG-S }\right)_{2}$ e UFRGS $\mathrm{F}_{2}\left(\mathrm{UF}-\mathrm{T}_{2}\right.$ e UF- $\left.\mathrm{S}_{2}\right)$ e San Gabriel $\mathrm{F}_{2}\left(\mathrm{SA}-\mathrm{S}_{2}\right.$, genótipo sensível). O genótipo $\mathrm{SA}-\mathrm{T}_{2}$ não foi utilizado, pois não foram obtidas sementes suficientes no segundo ciclo de seleção.

Eventualmente, as plantas mantidas nos vasos receberam tratamento contra fungos e insetos, com difenoconazol $(25 \% \mathrm{~m} / \mathrm{v})$ e deltametrina $(25 \% \mathrm{~m} / \mathrm{v})$, respectivamente. 
Após a coleta das sementes, os genótipos $\mathrm{F}_{2}$ foram testados em relação ao progresso alcançado, sendo comparados ao germoplasma original, em solo ácido contendo diferentes concentrações de alumínio.

O solo deste experimento foi coletado em janeiro de 2009 no município de André da Rocha (RS), seco ao ar, destorroado, peneirado e acondicionado em potes plásticos com capacidade para $1,5 \mathrm{~kg}$ e analisado (Tabela 1 ).

Realizaram-se em cinco repetições, de acordo com os resultados da análise físico-química do solo, aplicações de cinco níveis de calagem, em doses equivalentes a 0 ; 0,$10 ; 0,20 ; 0,40$ e 0,80 vezes a dose indicada pelo índice SMP para se obter $\mathrm{pH} 6,0$, com base nas recomendações da Comissão de Química e Fertilidade do Solo - RS/SC (2004). O valor 1,0 SMP para este solo foi de $7,5 \mathrm{tha}^{-1}$. Para a correção do solo, foi utilizada uma mistura de carbonato de cálcio e carbonato de magnésio (relação molar 3:1). Após a incubação, os tratamentos de correção da acidez do solo resultaram nos níveis de 41,$9 ; 25,1 ; 20,1 ; 4,8$ e $0 \%$ de saturação por alumínio.

Após 80 dias de incubação (5/4/2009), foram semeadas aproximadamente 10 sementes por vaso de cada um dos nove genótipos $\mathrm{F}_{2}$ selecionados e de todo o germoplasma original (quatro cultivares e uma população). Utilizou-se a alfafa crioula (Medicago sativa) como espécie testemunha, pela sua reconhecida sensibilidade ao alumínio em relação ao cornichão (Blumenthal \& McGraw, 1999).

Cada vaso recebeu aporte de $100 \mathrm{mg}$ de nitrogênio (nitrato de amônio), $100 \mathrm{mg} \mathrm{de} \mathrm{P}_{2} \mathrm{O}_{5}$ (superfosfato triplo) e $100 \mathrm{mg}$ de $\mathrm{K}_{2} \mathrm{O}$ (cloreto de potássio) na ocasião da semeadura. Foi realizado um desbaste de homogeneização quando as plantas apresentaram em média 2 a 3 folhas trifolioladas, deixando-se apenas cinco plantas por vaso.

Após 80 dias de crescimento (25/6/2009), essas plantas foram avaliadas para produção de matéria seca da parte aérea (MSPA) após secagem por 72 horas em estufa de circulação de ar forçada a $65^{\circ} \mathrm{C}$, área foliar (AF) com auxílio de um planímetro ótico (Licor, LI-6200), altura (H) com auxílio de uma régua graduada em $\mathrm{mm}$, número de folhas (NF) e de ramificações (R), pela contagem direta dessas características.
O delineamento experimental utilizado foi o completamente casualizado, com três repetições formadas, em média, de cinco plantas. Os dados foram submetidos à análise estatística com o auxílio do software SAS, v.8.0 (SAS Institute, 2001) pelos procedimentos Factorial ANOVA, constituindo-se uma análise de variância fatorial (genótipos $\times$ saturações por alumínio) para as variáveis: matéria seca da parte aérea, área foliar, altura, número de folhas e de ramificações. As médias foram comparadas pelo teste de Tukey a $5 \%$ de probabilidade quando houve significância para o teste $\mathrm{F}$.

A partir dos resultados obtidos, foi realizada análise de regressão para a matéria seca da parte aérea. Os demais resultados foram agrupados em uma matriz de distância pelo software NTSYS, sendo expressos em dendogramas. Adicionalmente, a matriz de correlação entre todas as variáveis foi gerada.

\section{Resultados e Discussão}

Para acúmulo de matéria seca da parte aérea, observou-se interação significativa $(\mathrm{P}=0,0004)$ entre os genótipos contrastantes (selecionados para tolerância e sensibilidade e germoplasma original) e o efeito da saturação por alumínio do solo (Tabela 2).

Os maiores acúmulos de matéria seca da parte aérea ocorreram na ausência de alumínio para todos os 15 genótipos avaliados. A alfafa apresentou maior produção de MSPA neste tratamento, acumulando 143,48 mg/planta. Entre os genótipos de L. corniculatus, o acúmulo de MSPA foi maior nos genótipos $\mathrm{UF}_{2} \mathrm{~T}_{2}, \mathrm{SA}-\mathrm{S}_{2}, \mathrm{DR}-\mathrm{T}_{2}$ e para as cultivares San Gabriel e Draco, variando entre 59 e $69 \mathrm{mg} /$ planta. O restante do germoplasma original e genótipos selecionados de cornichão não diferiram significativamente, apresentando valores entre 45 e $55 \mathrm{mg} /$ planta, exceto os genótipos UF-S ${ }_{2}$, $\mathrm{SG}_{-} \mathrm{S}_{2}$ e DR-S $\mathrm{S}_{2}$, e c cv. Estanzuela, que apresentaram menor acúmulo de MSPA nesta concentração de alumínio (valores entre 25 e $37 \mathrm{mg} /$ planta).

Em saturação por alumínio de 4,8\%, destacaram-se os genótipos UF- $\mathrm{T}_{2}, \mathrm{DR}-\mathrm{T}_{2}$ e a cv. Draco, com matéria seca da parte aérea variando entre 66,80 e $71,07 \mathrm{mg} /$ planta. Por outro

Tabela 1 - Caracterização físico-química do solo coletado no município de André da Rocha, Rio Grande do Sul

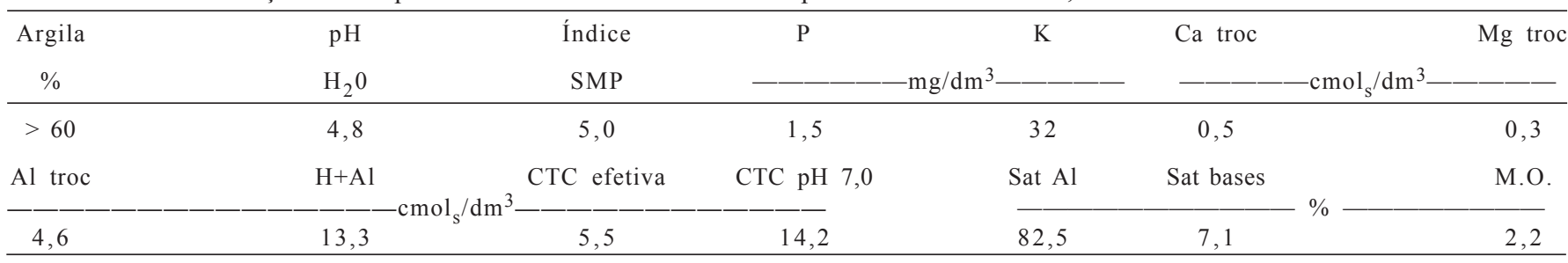


Tabela 2 - Matéria seca da parte aérea (MSPA) de cinco genótipos originais e nove populações de L. corniculatus contrastantes em relação à tolerância ao alumínio e de alfafa crioula (Medicago sativa)

\begin{tabular}{|c|c|c|c|c|c|c|}
\hline \multirow[t]{2}{*}{ Genótipo } & \multicolumn{5}{|c|}{ Saturação por alumínio (\%) } & \multirow[t]{2}{*}{ Média } \\
\hline & 41,9 & 25,1 & 20,1 & 4,8 & 0 & \\
\hline \multicolumn{7}{|c|}{ MSPA $\mathrm{mg} /$ planta } \\
\hline $\mathrm{UF}-\mathrm{T}_{2}$ & $32,33 \mathrm{Ab}$ & $39,27 \mathrm{Ab}$ & $36,93 \mathrm{Bb}$ & $66,80 \mathrm{Aa}$ & $61,35 \mathrm{Ba}$ & 47,34 \\
\hline $\mathrm{UF}-\mathrm{S}_{2}$ & $15,07 \mathrm{BCb}$ & $18,00 \mathrm{CDab}$ & $13,57 \mathrm{Db}$ & $13,27 \mathrm{~Eb}$ & $25,20 \mathrm{Da}$ & 17,02 \\
\hline SG & $14,87 \mathrm{Cc}$ & $12,53 \mathrm{Dc}$ & $27,73 \mathrm{Cb}$ & $43,73 \mathrm{Ca}$ & $46,23 \mathrm{Ca}$ & 29,02 \\
\hline $\mathrm{SAN}^{2}$ & $22,73 \mathrm{BCc}$ & $41,67 \mathrm{Ab}$ & $29,93 \mathrm{BCc}$ & $59,87 \mathrm{Ba}$ & $59,25 \mathrm{Ba}$ & 42,69 \\
\hline $\mathrm{SA}-\mathrm{S}_{2}$ & $11,17 \mathrm{Cc}$ & $24,30 \mathrm{BCb}$ & $18,93 \mathrm{Dbc}$ & $24,53 \mathrm{Db}$ & $61,27 \mathrm{Ba}$ & 28,04 \\
\hline EST & $13,57 \mathrm{Cc}$ & $22,53 \mathrm{Cb}$ & $32,97 \mathrm{Ba}$ & $38,07 \mathrm{CDa}$ & $37,80 \mathrm{CDa}$ & 28,99 \\
\hline $\mathrm{ES}-\mathrm{T}_{2}$ & $19,00 \mathrm{BCc}$ & $31,67 \mathrm{Bb}$ & $49,47 \mathrm{Aa}$ & $58,73 \mathrm{Ba}$ & $51,64 \mathrm{Ba}$ & 42,10 \\
\hline $\mathrm{ES}_{-} \mathrm{S}_{2}$ & $9,29 \mathrm{CDc}$ & $26,05 \mathrm{BCb}$ & $24,20 \mathrm{Cb}$ & $48,13 \mathrm{Ca}$ & $50,25 \mathrm{Ba}$ & 31,58 \\
\hline DRACO & $13,47 \mathrm{Cc}$ & $12,42 \mathrm{Dc}$ & $37,07 \mathrm{Bb}$ & $68,00 \mathrm{Aa}$ & $69,25 \mathrm{Ba}$ & 40,04 \\
\hline
\end{tabular}

Letras minúsculas indicam diferença nas linhas a $5 \%$ de probabilidade pelo teste de Tukey.

Letras maiúsculas indicam diferença nas colunas a $5 \%$ de probabilidade pelo teste de Tukey.

lado, os genótipos $\mathrm{SG}-\mathrm{S}_{2}$, DR-S 2 e UF- $\mathrm{S}_{2}$ foram os menos produtivos neste tratamento, com matéria seca da parte aérea variando entre 13,27 e $20,27 \mathrm{mg} /$ planta.

De forma geral, em saturações moderadas de alumínio (20,1\%), destacaram-se os quatro genótipos selecionados para tolerância (UF-T $2, \mathrm{SG}_{2}, \mathrm{~T}_{2}, \mathrm{ES}-\mathrm{T}_{2}$ e DR- $\mathrm{T}_{2}$ ), assim como a população UFRGS e as cultivares Draco e San Gabriel (MSPA entre 29,93 e 49,47 mg/planta). Repetindo a tendência observada nos tratamentos anteriores, os genótipos DR-S $\mathrm{S}_{2}$, SA-S e UF-S $_{2}$ foram os que apresentaram menor MSPA, com valores entre 13,57 e $18,93 \mathrm{mg} /$ planta.

Nos níveis mais elevados de alumínio $(25,1$ e $41,9 \%$ de saturação), destacaram-se os genótipos tolerantes, $\mathrm{UF}_{2} \mathrm{~T}_{2}, \mathrm{SG}_{2}, \mathrm{~T}_{2}, \mathrm{EST}_{2} \mathrm{~T}_{2}$ e DR-T 2 , e a cultivar San Gabriel. Na saturação de $41,9 \%$, todos os genótipos selecionados para sensibilidade ao alumínio apresentaram baixo acúmulo de matéria seca de produção aérea, com valores abaixo de $10 \mathrm{mg} /$ planta, exceto UF-S 2 com 15,07 mg/planta. Apesar de o efeito inibitório do alumínio incidir inicialmente no ápice radicular, em médio prazo, o efeito desse metal causa redução da área e do volume de solo explorado pelo sistema radicular, causando redução no desenvolvimento também da parte aérea da planta (Marshner, 1995).

A alta sensibilidade da alfafa pode ser confirmada por meio de comparação entre os níveis de baixa saturação por alumínio $(4,8 \%)$ e na ausência de alumínio tóxico $(0 \%)$. Observou-se na análise redução altamente significativa da matéria seca da parte aérea em alfafa (mais de 60\%), enquanto, para todo o germoplasma original e para os genótipos tolerantes de cornichão, a matéria seca da parte aérea manteve-se inalterada $(\mathrm{P}>0,05)$. Os genótipos de cornichão selecionados pela sensibilidade ao alumínio também apresentaram redução $(\mathrm{P}<0,05)$ na matéria seca da parte aérea nesta comparação, exceto o genótipo ES-S, que manteve níveis de matéria seca da parte aérea semelhantes.

Já a comparação da matéria seca da parte aérea entre a ausência de alumínio e um nível moderado de alumínio (20,1\% de saturação) comprova que o genótipo ES-T 2 apresentou apenas $4 \%$ de redução da matéria seca da parte aérea em relação à ausência de alumínio. Os genótipos SG- $\mathrm{T}_{2}$ e ES- $\mathrm{T}_{2}$ mantiveram reduções de cerca de $20 \%$ e foram seguidos pelo genótipo UF-T ${ }_{2}$, com $35 \%$ de redução da matéria seca da parte aérea. Os demais genótipos de cornichão apresentaram reduções entre 40 e 50\% dessa variável para esta comparação. Já a alfafa apresentou redução de 71,6\% em relação à ausência de toxidez por alumínio, sendo a espécie mais sensível à saturação por alumínio.

Na comparação entre o nível $25,1 \%$ e a ausência de saturação por alumínio, a maior diversidade de resposta foi observada entre o germoplasma e seus genótipos contrastantes ao alumínio. Como mais tolerantes neste nível, mantiveram-se a cultivar San Gabriel, a população UFRGS e o genótipo UF- $\mathrm{T}_{2}$, que apresentaram cerca de 30 a $35 \%$ de redução da matéria seca da parte aérea. Já a população Estanzuela e seu genótipo selecionado pela tolerância $\left(E S-\mathrm{T}_{2}\right)$ apresentaram $40 \%$ de redução da matéria seca da parte aérea. Por outro lado, as cultivares São Gabriel e Draco foram as que mais sofreram efeito do alumínio tóxico nesta concentração, apresentando reduções de 73 e $83 \%$, respectivamente, no entanto, seus genótipos selecionados 
pela tolerância, $\mathrm{SG}-\mathrm{T}_{2}$ e DR- $\mathrm{T}_{2}$ foram superiores aos seus parentais nesta comparação e apresentaram redução da matéria seca da parte aérea de aproximadamente $53 \%$. Esses resultados indicam que dois ciclos de seleção visando tolerância ao alumínio permitiram aumento do acúmulo de matéria seca da parte aérea em situações de moderada saturação por alumínio $(25,1 \%)$ para os genótipos selecionados a partir das cultivares Draco $\left(\mathrm{DR}-\mathrm{T}_{2}\right)$ e São Gabriel(SG- $\left.\mathrm{T}_{2}\right)$.

Entre a ausência de alumínio e o nível mais elevado de saturação por alumínio (41,9\%), observa-se que os genótipos UF- $\mathrm{T}_{2}$ e SG-T 2 apresentaram redução de $48 \%$ e 54\% da matéria seca da parte aérea produzida na ausência de alumínio, respectivamente. Todos os demais genótipos de cornichão apresentaram entre $60 \%$ e $70 \%$ de redução na matéria seca da parte aérea, exceto a cultivar Draco, com $81,1 \%$ da redução relativa ao tratamento sem alumínio, comprovando que o germoplasma de cornichão é mais sensível ao alumínio. A alfafa, por sua vez, apresentou redução de $97,4 \%$ em relação ao tratamento sem alumínio tóxico, confirmando ser uma espécie extremamente sensível ao alumínio.

A realização dessas comparações permitiu a identificação do nível de alumínio que apresentou maior variação entre germoplasmas $(25,1 \%)$. Este nível é semelhante ao observado em trabalhos anteriores (Santos, 2009), que descreveram valores próximos a 30\% de alumínio como mais adequados na observação da variabilidade de resposta de germoplasma de cornichão. Adicionalmente, nesses níveis destacaram-se a cultivar San Gabriel, a população UFRGS e seu genótipo selecionado para tolerância ao alumínio (UF- $\left.\mathrm{T}_{2}\right)$.

Observando-se a produção de matéria seca da parte aérea individual de cada população e de suas seleções, verificou-se que a produção da população UFRGS (Figura 1A) decresceu linearmente à medida que aumentou a saturação por alumínio até cerca de $20 \mathrm{mg}$ /planta no nível de $41,9 \%$ de alumínio.

Uma resposta linear também é observada para o genótipo UF-S ${ }_{2}$. No entanto, a matéria seca da parte aérea neste caso se mantém em níveis reduzidos, praticamente inalterados, ao longo das diferentes saturações de alumínio. Já o genótipo UF- $\mathrm{T}_{2}$ apresentou maiores produções de matéria seca da parte aérea, com um comportamento quadrático, ou seja, redução de até $20 \%$ de alumínio e manutenção da matéria seca da parte aérea após esta saturação.

Em análise da produção de matéria seca da parte aérea da cv. Draco e de seus genótipos contrastantes (Figura 1B), observou-se que, assim como para a população UFRGS, houve decréscimo linear dessa variável. No entanto, o coeficiente angular para a cv. Draco foi superior, ou seja, à medida que aumentou a saturação por alumínio, a produção de matéria seca da parte aérea decresceu mais drasticamente. Nesta cultivar, a produção foi de cerca de $70 \mathrm{mg} /$ planta de matéria seca da parte aérea na ausência de alumínio, enquanto a regressão da população UFRGS estimou matéria seca da parte aérea de menos de $50 \mathrm{mg} /$ planta. Já na saturação $42 \%$, a estimativa para a população UFRGS ficou próxima a $20 \mathrm{mg} / \mathrm{planta}$, enquanto, para a cv. Draco, ficou abaixo de $10 \mathrm{mg} /$ planta. O comportamento do genótipo DR-T $\mathrm{T}_{2}$ foi quadrático, sendo semelhante ao germoplasma original até níveis próximos a $25 \%$ de alumínio. A partir deste nível, manteve tendência de estabilidade, com matéria seca da parte aérea estimada de $20 \mathrm{mg} /$ planta em condições de $42 \%$ de saturação por alumínio. O genótipo DR- $\mathrm{S}_{2}$ manteve teores de MSPA baixos e semelhantes entre níveis de alumínio, resposta semelhante ao genótipo UF-S ${ }_{2}$.

Para as cultivares São Gabriel, San Gabriel e Estanzuela, o comportamento linear observado para a evolução da matéria seca da parte aérea em diferentes concentrações de alumínio foi semelhante ao descrito para a população UFRGS e para a cv. Draco (Figura 1C, 1D e 1E). Para os genótipos $\mathrm{SG}_{2} \mathrm{~T}_{2}$ e ES- $\mathrm{T}_{2}$, observou-se também comportamento linear, com estimativas de acúmulo de matéria seca da parte aérea superior à do germoplasma original em todas as saturações por alumínio. Já nos genótipos sensíveis, $\mathrm{SG}-\mathrm{S}_{2}$ e $\mathrm{SA}-\mathrm{S}_{2}$, observou-se redução dessa variável em situações de baixa e moderada saturação por alumínio. O genótipo ES-S $\mathrm{S}_{2}$ apresentou comportamento similar ao do seu germoplasma de origem, sendo ligeiramente superior em níveis de baixa saturação por alumínio e inferior a partir de $25 \%$ de alumínio no solo.

Para as demais características (AF, NF, R, H), foram realizadas análises conjuntas para cada concentração de alumínio, com cálculo da similaridade média entre os materiais. Assim, são apresentados neste estudo os resultados obtidos na ausência de alumínio ( $0 \%$ saturação) e com as concentrações moderada $(25,1 \%)$ e alta $(41,9 \%)$. Os agrupamentos segregaram as cultivares e população UFRGS e dos genótipos contrastantes em um padrão semelhante ao observado para matéria seca da parte aérea. Dessa forma, esses grupos formados serão tratados como: de alta produção; de baixa produção; ou de produção intermediária.

A similaridade média na ausência do alumínio foi de 17,37 (Figura 2). Foram formados três grupos distintos que seguiram comportamento semelhante ao observado para a matéria seca da parte aérea.

O primeiro grupo foi formado pela população UFRGS e pelas cultivares São Gabriel e Estanzuela, além dos 

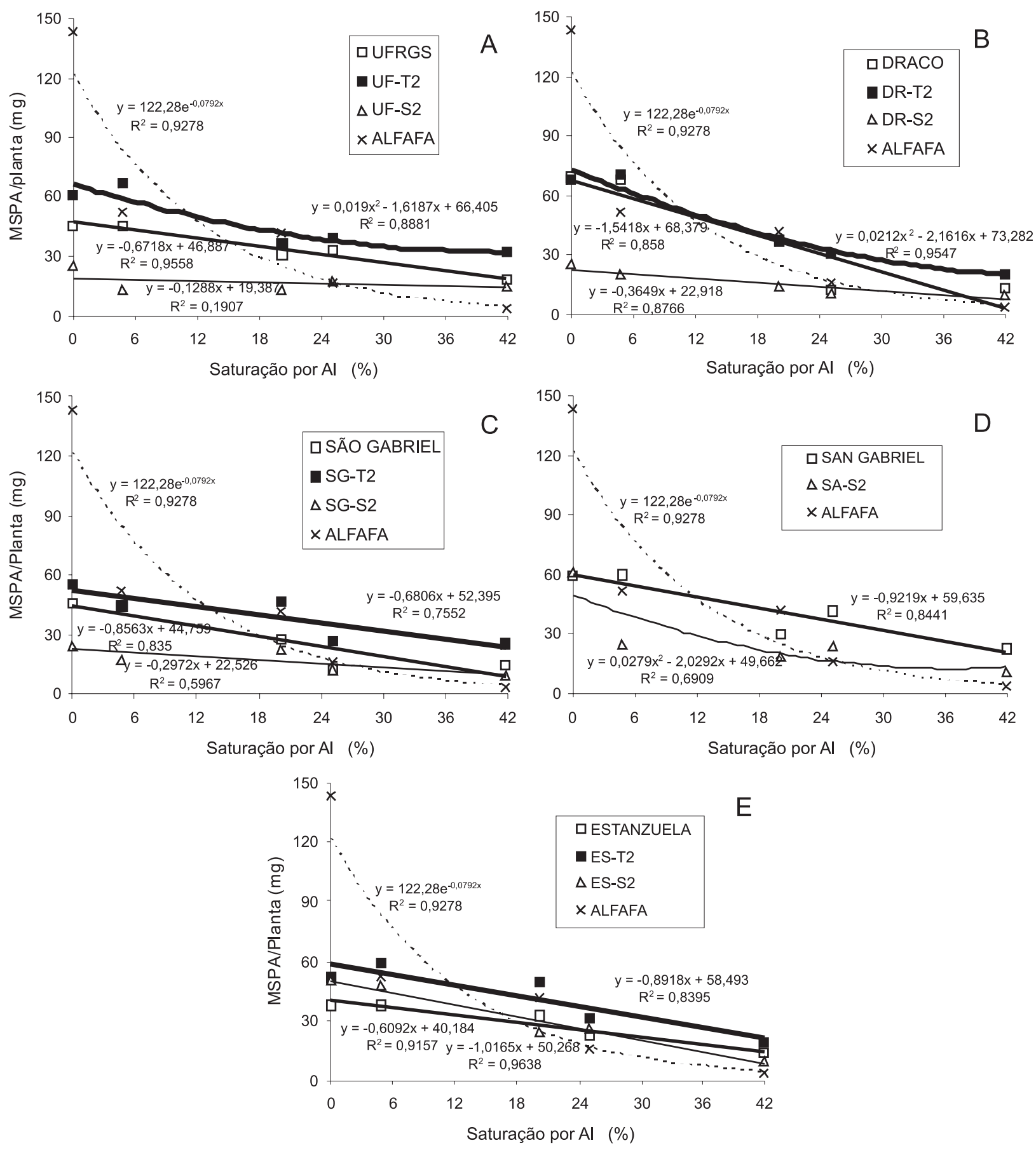

$\mathrm{A}=\mathrm{UFRGS}$; $\mathrm{B}=$ Draco; $\mathrm{C}=$ São Gabriel; $\mathrm{D}=$ San Gabriel; e E = Estanzuela

Figura 1 - Análise de regressão para matéria seca da parte aérea de germoplasmas de L. corniculatus e suas respectivas populações contrastantes aos níveis de saturação por alumínio no solo.

genótipos contrastantes para esta última cultivar (ES- $\mathrm{T}_{2}$ e ES-S 2 ). Nesse grupo, encontram-se plantas com comportamento intermediário, ou seja, medianamente produtivas na ausência de alumínio. Já o segundo grupo foi formado pelas cultivares Draco e San Gabriel, além

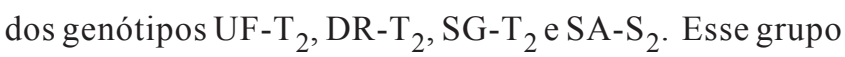
representa genótipos com maior número de folhas, área foliar e altura, fatores determinantes para maior acúmulo de matéria seca da parte aérea. O terceiro grupo, formado por três genótipos selecionados para sensibilidade ao alumínio (UF-S $\mathrm{S}_{2}, \mathrm{SG}-\mathrm{S}_{2}$ e DR-S $\mathrm{S}_{2}$ ), foi coincidente com os genótipos menos produtivos. Por se tratar de um nível isento de alumínio tóxico, pode-se ponderar que a seleção destes genótipos sensíveis tenha resultado em plantas com baixo vigor, e não para menor tolerância ao alumínio tóxico. 


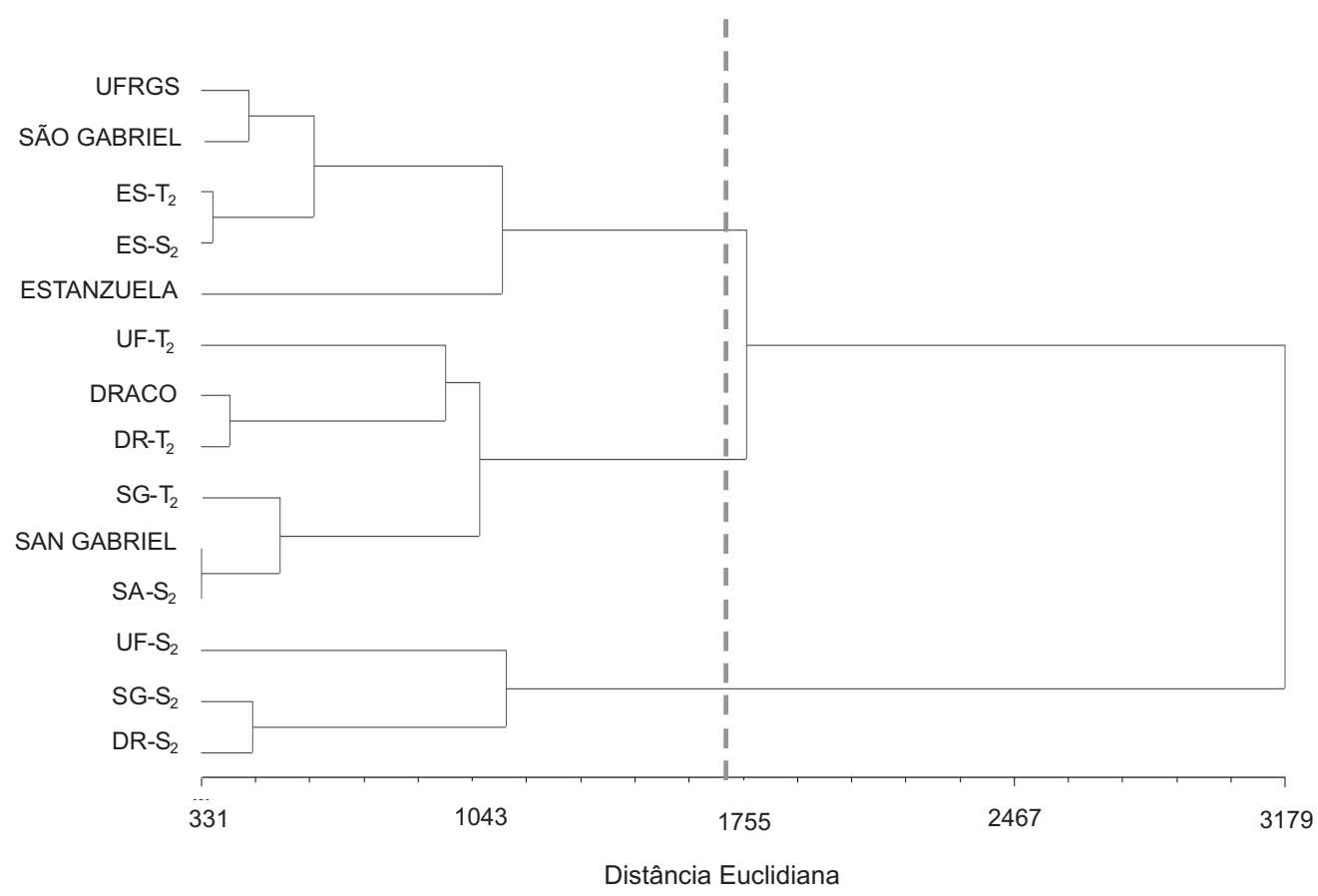

Figura 2 - Distância Euclidiana (dissimilaridade) em 14 materiais de Lotus corniculatus submetidos a $0 \%$ de saturação por alumínio no solo. Média $=17.37$.

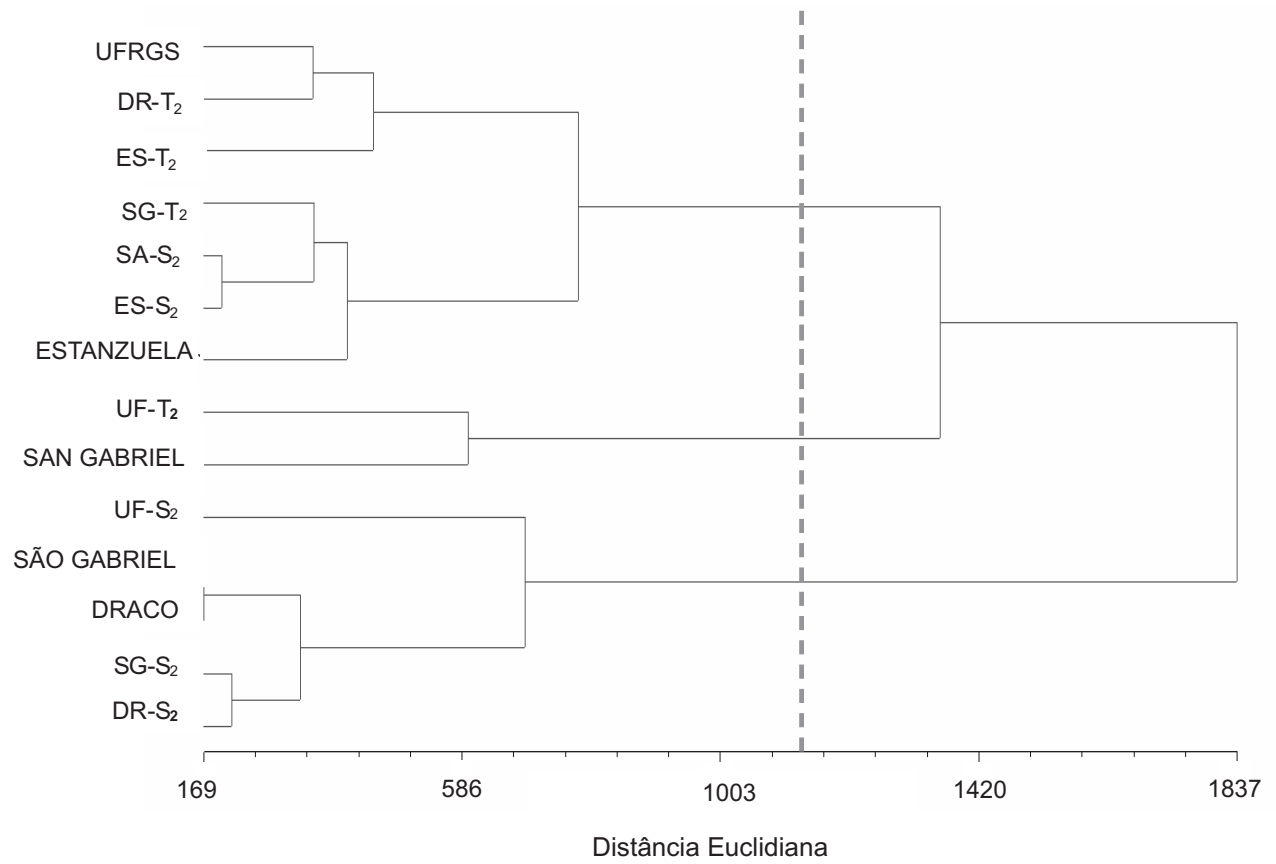

Figura 3 - Distância Euclidiana (dissimilaridade) em 14 materiais de Lotus corniculatus submetidos a 25,1\% de saturação por alumínio no solo. Média $=11,40$.

No tratamento com moderada toxidez por alumínio (25,1\% de saturação), também foi observada a formação de três grupos (Figura 3), com similaridade média de 11,40 para esse tratamento.

$\mathrm{Na}$ análise conjunta da AF, NF, A e R, os genótipos $\mathrm{UF}-\mathrm{T}_{2}$ e a cv. San Gabriel apresentaram as maiores produções, formando o primeiro grupo. Um segundo grupo formado pela população UFRGS, pela cv. Estanzuela e pelos genótipos DR-T 2, ES- $\mathrm{T}_{2}, \mathrm{SG}_{2} \mathrm{~T}_{2}, \mathrm{ES}-\mathrm{S}_{2}$ e SA-S 2 apresentou comportamento intermediário, enquanto o terceiro grupo, formado pelas cultivares Draco e São Gabriel e pelos genótipos DR-S ${ }_{2}$, SG-S $S_{2}$ e UF-S ${ }_{2}$, 
destacou-se pela sensibilidade nesta concentração de alumínio.

No tratamento com elevada saturação por alumínio (41,9\%), também se observou formação de três grupos, novamente apresentando comportamento bem distinto dos demais (Figura 4). O genótipo UF- $\mathrm{T}_{2}$ foi superior neste tratamento, isolando-se de todos os demais genótipos. O segundo grupo foi formado pela população UFRGS e pela cv. San Gabriel, além dos genótipos $\mathrm{SG}_{2} \mathrm{~T}_{2}, \mathrm{DR}-\mathrm{T}_{2}$ e ES- $\mathrm{T}_{2}$. Neste grupo encontram-se as plantas com moderada produção neste nível de alumínio. O último grupo, formado pelos demais genótipos, apresentou severa limitação neste tratamento.

A comparação das similaridades médias permite observar a variabilidade em cada nível analisado. $\mathrm{Na}$ ausência do estresse por alumínio, houve maior similaridade média, ou seja, alta variabilidade do germoplasma. À medida que aumentou a saturação por alumínio do solo, a variabilidade tendeu a diminuir, chegando a valores de 7,78 em situações de alta toxidez (41,9\%), enquanto em condições de moderada/alta toxidez ( $25,1 \%$ de alumínio) a similaridade média foi de 11,4. Esses resultados confirmam a observação realizada na análise da matéria seca da parte aérea, em que o nível de $25,1 \%$ de saturação por alumínio foi o que melhor expressou a variabilidade do germoplasma de cornichão estudado.

De acordo com os resultados da análise de correlação, observam-se valores elevados e significativos entre algumas das características de interesse. O principal destaque dessa análise foi a elevada correlação entre: $\mathrm{He} \mathrm{AF}(\mathrm{r}=0,71) ; \mathrm{He}$ MSPA $(r=0,70)$; e AF e MSPA $(r=0,99)$. Essas relações comprovam que a seleção de plantas de cornichão mais altas, ou com maior área foliar, condizem com plantas que apresentam maior matéria seca da parte aérea em situações com presença de alumínio tóxico.

A análise crítica geral dos resultados comprovou que as quatro cultivares avaliadas, a população UFRGS e os genótipos selecionados variaram amplamente seu comportamento de acordo com o teor de alumínio tóxico no solo. Na ausência de alumínio tóxico, foram observadas maiores produções, tanto em germoplasma original quanto em genótipos contrastantes ao alumínio. Esse comportamento pode ser explicado pela ausência da interferência do alumínio, oportunizando as plantas a maximizar seu potencial genético. Em situações de moderada toxidez, destacaram-se a cv. Uruguaia San Gabriel e o genótipo UF-T 2 , enquanto as cvs. Draco e São Gabriel apresentaram redução já nesta concentração de alumínio. Em níveis elevados de alumínio, o genótipo $\mathrm{UF}_{-} \mathrm{T}_{2}$ foi superior aos demais, demonstrando que a seleção realizada neste genótipo favoreceu a manutenção dos componentes de rendimento da matéria seca da parte aérea. Esse comportamento pode ser função de um mecanismo de tolerância mais desenvolvido neste genótipo selecionado para tolerância ao alumínio. Em experimentos para avaliação da exsudação de ácidos orgânicos, observou-se

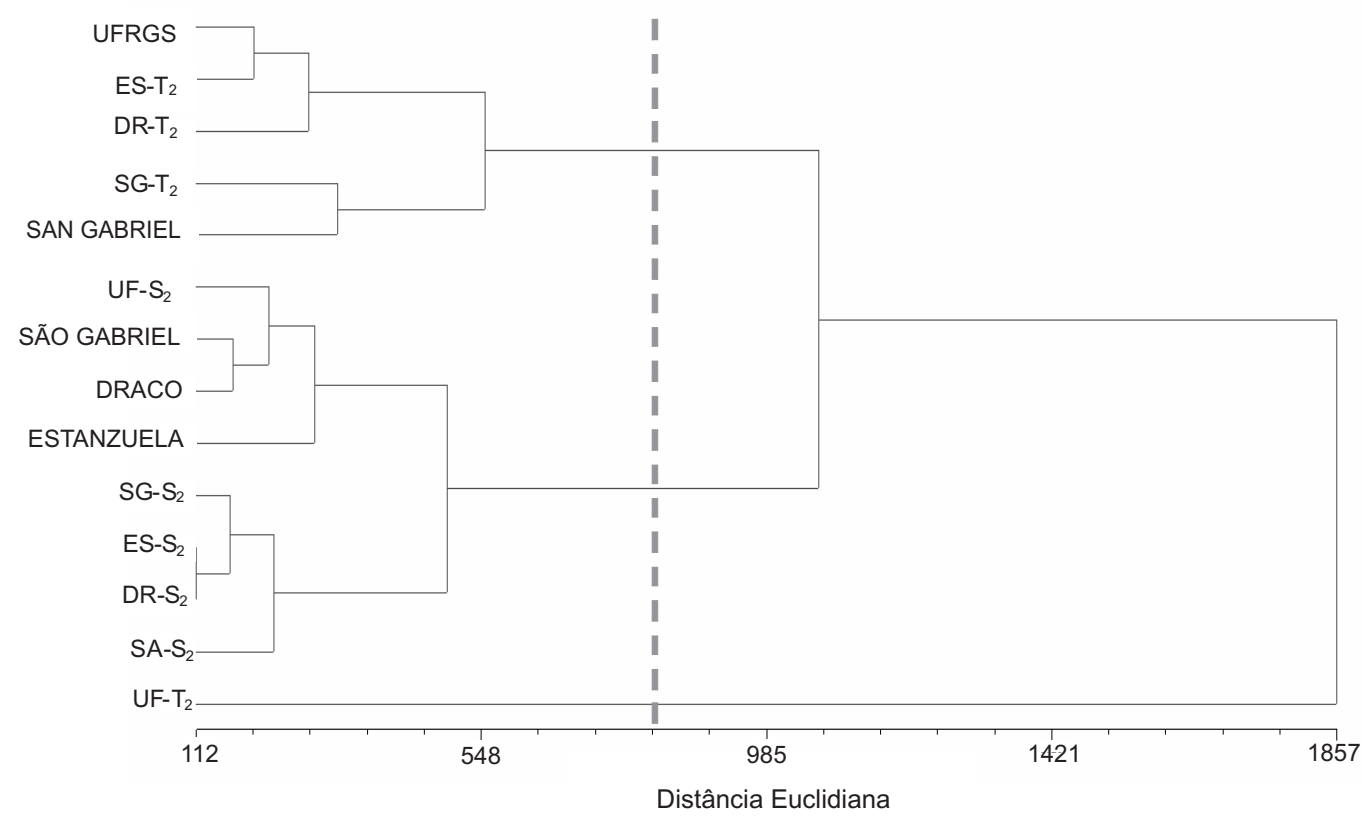

Figura 4 - Distância Euclidiana (dissimilaridade) em 14 materiais de Lotus corniculatus submetidos a 41,9\% de saturação por alumínio no solo. Média $=7.78$. 
incremento significativo neste genótipo (Santos, 2009). Neste nível drástico, a população UFRGS e a cv. San Gabriel demonstraram ser materiais com algum nível de tolerância ao alumínio tóxico.

\section{Conclusões}

A seleção para tolerância ao alumínio aumenta a tolerância dos genótipos estudados, aumentando também a produção de matéria seca da parte aérea na ausência de alumínio em três dos quatro genótipos selecionados para esta finalidade. Já a seleção visando sensibilidade ao alumínio resulta em plantas com baixo vigor. A saturação de $25,1 \%$ por alumínio é a que promove maior variabilidade entre os genótipos testados, mostrando-se adequada para a seleção de plantas de cornichão visando tolerância à toxidez por alumínio. Os genótipos tolerantes UF- $\mathrm{T}_{2}$, $\mathrm{SG}-\mathrm{T}_{2}$ e DR- $\mathrm{T}_{2}$ são os recomendados para a continuidade do trabalho de melhoramento, uma vez que apresentaram os comportamentos esperados para tolerância ao alumínio.

\section{Referências}

BLUMENTHAL, M.J.; McGRAW, R.L. Lotus adaptation, use and manageament. In: BEUSELINCK, P.R. (Ed.). Trefoil: the science and technology of Lotus. Madison: The American Society of Agronomy, 1999. p.1-20.

COMISSÃO DE QUÍMICA E FERTILIDADE DO SOLO RS/SC CQFS-RS/SC. Manual de adubação e de calagem para os estados do Rio Grande do Sul e Santa Catarina. 10.ed. Porto Alegre: SBCS/Núcleo Regional Sul, UFRGS, 2004. 400p.
DÍAZ P.; MONZA, J.; MÁRQUEZ, A. Drought and saline stress in Lotus japonicus. In: MÁRQUEZ, A. (Ed.). Lotus japonicus Handbook. Oxford: Springer, 2005. 108p.

FOY, C.D.; CHANEY, R.L.; WHITE, M.C. The phisiology of metal toxicity in plants. Annual Reviews Plant Physiology, v.29, n.1, p.511-566, 1978.

KIRKBRIDE, J.H. Lotus systematics and distribuition. In BEUSELINCK, P.R. (Ed.). Trefoil: the science and technology of Lotus. Madison: The American Society of Agronomy, 1999. p.1-20.

KOCHIAN, L.V.; PIÑEROS, M.; HOEKENGA, O.A. The physiology, genetics and molecular biology of plant aluminum resistance and toxicity. Plant and Soil, v.274, p.175-195, 2005.

MARSCHNER, H. Mineral nutrition of higher plants. London: Academic Press Inc., 1995. 446p.

PAPADOPOULOS, A.; KELMAN, W.M. Traditional breeding of Lotus species. In: BEUSEULINK, P.R. (Ed.). Trefoil: The Science and Technology of the Lotus. Madison: The American Society of Agronomy, 1999. p.187-198.

PAVLOVKIN, J.; PAL'OVE-BALANG, P.; KOLAROVIC, L. et al Growth and functional responses of different cultivars of Lotus corniculatus to aluminum and low pH stress. Journal of Plant Physiology, doi:10.1016/j.jplph.2009.03.005

RAO, I.M.; ZEIGER, R.S.; VERA, R. et al. Selection and breeding for acid-soil tolerance in crops. Bioscience, v.43, n.7, p.454-465, 1993

SAMAC, D.A.; TESFAYE, M. Plant improvement for tolerance to aluminum in acid soils - a review. Plant Cell, Tissue and Organ Culture, v.75, p.189-207, 2003.

SANTOS, A.M. Melhoramento genético de Lotus corniculatus visando tolerância à toxidez por alumínio. 2009. $203 \mathrm{f}$ Tese (Doutorado) - Programa de Pós-Graduação em Zootecnia, Faculdade de Agronomia, Universidade Federal do Rio Grande do Sul, Porto Alegre.

SAS Institute. System for Information. Versão 8.2. Cary, 2001. $392 p$.

STEINER, J.J. Birdsfoot trefoil origins asn germoplasm diversity. In: BEUSEULINK, P.R. (Ed.). Trefoil: The Science and Technology of the Lotus. Madison: The American Society of Agronomy, 1999. p.81-96.

VON UEXKÜLL, H.R.; MUTERT, E. Global extent, development and economic impact of acid soils. Plant and Soil, v.171, p.1-15, 1995. 